\title{
IDENTIFICAÇÃO E INTERVENÇÃO EM ATITUDES DE RISCO DE USUÁRIOS DE UMA UNIDADE DE ALIMENTAÇÃO E NUTRIÇÃO.
}

\author{
Fabiana Kurokawa Hasimoto ${ }^{1}$ \\ Flávia Queiroga Aranha ${ }^{2}$
}

\section{Resumo}

O estudo teve como objetivo identificar as atitudes de risco dos usuários de uma Unidade de Alimentação e Nutrição (UAN) localizada em Botucatu/SP, correlacioná-las à segurança dos alimentos e observar se houveram modificações comportamentais após intervenção educativa indireta. Trata-se de uma análise qualitativa exploratória, com técnica de observação não participante. Em um primeiro momento, procurou-se identificar as atitudes de risco mais comuns entre os usuários, para posteriormente, elaborar materiais educativos relacionando a conduta durante o autosserviço aos possíveis riscos de contaminação de alimentos, e assim, verificar se houveram mudanças comportamentais. A falta de higienização das mãos foi vista como um dos pontos mais importantes a serem trabalhados, já que nenhum dos comensais realizava tal atitude. Conseguiu-se observar pequenas mudanças no comportamento de alguns usuários, mostrando que medidas educativas devem ser aplicadas continuamente para uma melhor conscientização e geração de maiores efeitos.

Palavras-chave: Contaminação de alimentos, Consumidor, Atitudes de risco, Serviços de alimentação.

\section{Introdução}

Nas últimas décadas, intensas transformações foram observadas devido ao desenvolvimento industrial. Dentre elas, destacam-se a mudança no estilo de vida e nos hábitos alimentares da população. Essas modificações podem ser atribuídas à intensa urbanização, longos deslocamentos, extensa jornada de trabalho, profissionalização das mulheres, e maior acesso ao lazer e educação.

Como consequência, um tempo cada vez menor tem sido dedicado ao preparo e consumo dos alimentos, aumentando o número de refeições feitas fora do lar (AKUTSU et al., 2005; LEAL, 2010).

Dessa forma, atualmente, há uma maior busca dos consumidores pelos serviços de alimentação. Muitas empresas visando à saúde e produtividade de seus trabalhadores 
oferece refeições no próprio local de trabalho, frequentemente, através de empresas terceirizadas especialistas no ramo.

As unidades de trabalho onde são desenvolvidas as atividades de produção e distribuição de refeições para coletividades enfermas ou sadias são denominadas unidades de alimentação e nutrição (UANs) (CONSELHO FEDERAL DE NUTRICIONISTAS, 2018). Uma modalidade de serviço muito comum adotada nesses locais é o self-service, sistema com atendimento ágil que oferece diversas opções de alimentos, permitindo que a própria clientela componha seu prato de acordo com suas escolhas (SÁVIO et al., 2005; SILVA JUNIOR, 1995).

Assim, busca-se oferecer uma alimentação de qualidade a clientes cada vez mais exigentes tanto com a variedade como com a segurança higiênico-sanitária dos alimentos. Smith e Fratamico (1995) ressaltam que a preocupação com as condições higiênicosanitárias deve ser de extrema importância, já que a presença de micro-organismos patogênicos pode provocar infecções e intoxicações alimentares, as chamadas doenças transmitidas pelos alimentos (DTAs).

Os alimentos estão constantemente expostos à contaminação, logo na sua produção, passando pelo seu transporte, recepção e armazenamento, até a sua manipulação e distribuição. A contaminação de alimentos é uma das maiores causas de doenças e, por consequência, de internações hospitalares. Todos que participam da cadeia produtiva possuem a responsabilidade de oferecer alimentos seguros, desde o produtor até o consumidor final (HOBBS; ROBERTS, 1998).

Geralmente, destaca-se a importância dos manipuladores de alimentos para assegurar alimentação de qualidade. Exige-se que os funcionários de uma UAN sejam devidamente capacitados em segurança, higiene e saúde no trabalho, conscientes sobre o papel que desempenham na prevenção de DTAs (VEIROS; SMITH; PROENÇA, 2006).

No entanto, os comensais ao adotar certas atitudes também podem ser responsáveis pela contaminação dos alimentos, principalmente, em um serviço de self-service, onde entram diretamente em contato com os alimentos. Segundo Evangelista (2002), a contaminação pode ocorrer pela fala, por espirros e tosses que espalham gotículas repletas de micro-organismos; pela falta de higiene, incluindo a transgressão da lavagem de mãos 
após a utilização do sanitário, tocar objetos e antes das refeições; ou práticas como coçar e esfregar o nariz, olhos, boca, cabelos, entre outras partes do corpo.

Diante disso, percebe-se quRee a inocuidade do alimento depende de diversas situações, devendo considerar os pontos que fogem do controle do processador. Assim, este estudo teve por objetivo identificar as atitudes de risco dos usuários de uma UAN, correlacioná-las com a segurança alimentar, e observar se houveram modificações após intervenção educativa.

\section{Metodologia}

O estudo foi desenvolvido em uma UAN de uma empresa localizada no município de Botucatu, SP. Durante o horário de almoço, esse local é frequentado diariamente por cerca de 100 a 120 pessoas, incluindo funcionários pertencentes ao quadro da empresa, terceirizados e alguns visitantes. O sistema de distribuição adotado é o self-service parcial, em que o porcionamento dos pratos principais é feito por um colaborador e o restante pelo próprio consumidor.

Realizou-se uma análise qualitativa exploratória, com técnica de observação não participante, ou seja, os usuários não sabiam que estavam sendo observados quanto às suas atitudes ao manipular os alimentos. A pesquisa foi desenvolvida em duas etapas. $\mathrm{Na}$ primeira, procurou-se identificar quais eram as atitudes de risco mais comuns praticadas pelos comensais no momento do autosserviço, durante uma semana. Sendo elas: (1) não lavar as mãos imediatamente antes de realizar a refeição; (2) mexer no cabelo perto das preparações expostas no balcão; (3) coçar ou esfregar a boca e nariz ao se servir; (4) falar sobre as preparações expostas no balcão; (5) utilizar o utensílio de uma preparação em outra para se servir; (6) devolver alimentos do prato às cubas com a mão ou utensílio das preparações; (7) arrumar os alimentos do prato com os utensílios das preparações; (8) e utilizar aparelhos celulares ao se servir.

Em seguida, elaborou-se material educativo para uma intervenção indireta. O material formulado continha informações sobre as DTAs e com base nas atitudes verificadas anteriormente orientava os usuários em como ajudar na prevenção das mesmas. Foram desenvolvidos folhetos (Figura 1), para serem dispostos em displays nas mesas do refeitório. 


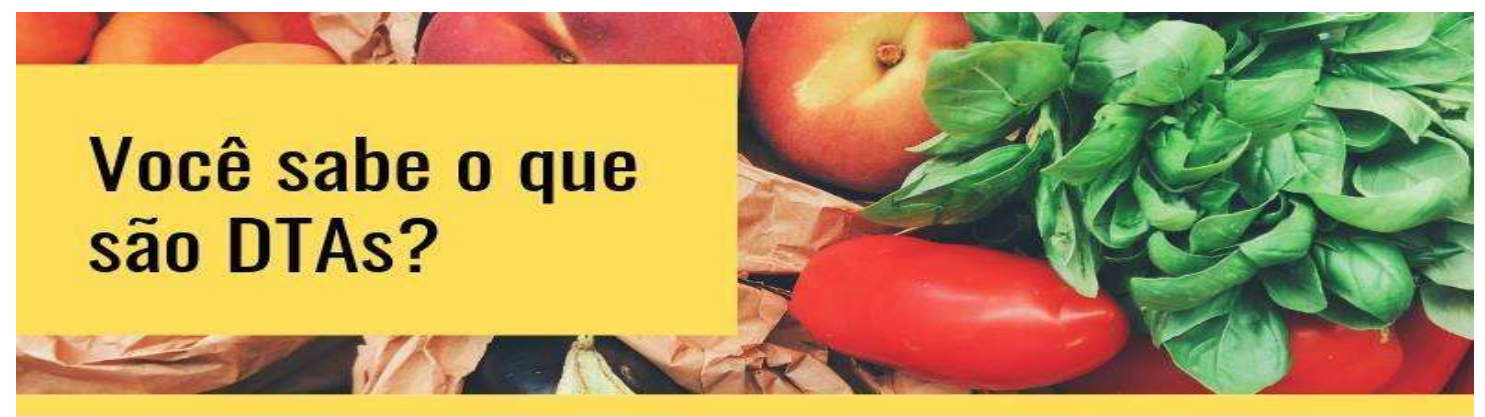

\section{DTAs - Doenças Transmitidas por Alimentos}

DTAs são Doenças Transmitidas por Alimentos causadas pela ingestão de alimentos, bebidas e água contaminados por bactérias, vírus, parasitas e/ou toxinas.

Os sintomas mais comuns são diarreia, náuseas, vômitos, cólicas abdominais, mal-estar e febre.

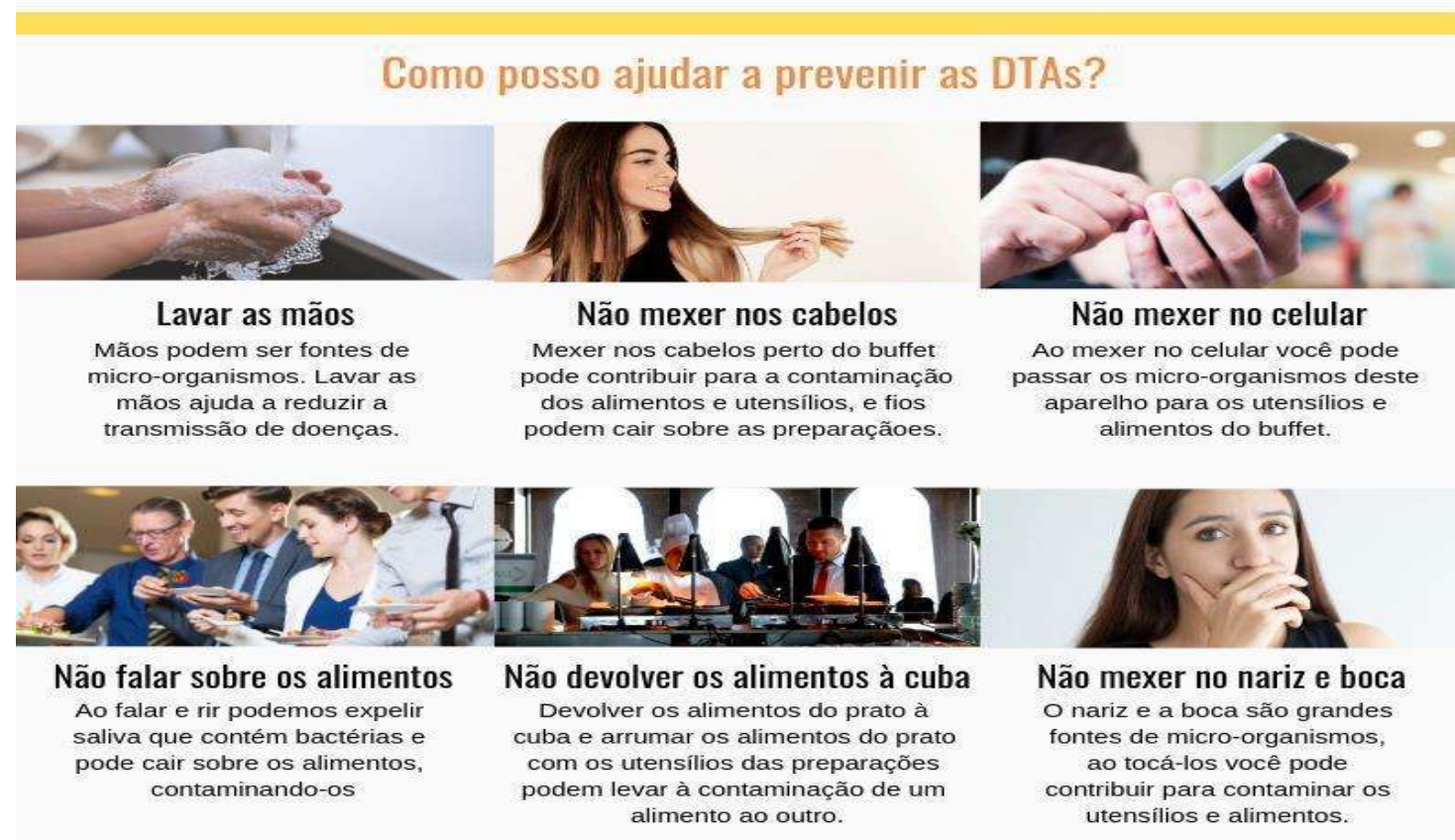

Figura 1 - Displays educativos.

Após a implementação da intervenção, iniciou-se um segundo momento de observação. Durante duas semanas procurou-se verificar se o material havia surtido efeito e provocado mudanças, mesmo que pequenas, nos comportamentos dos usuários.

\section{Resultados e Discussão}

Constatou-se que a lavagem de mãos figura como um dos principais pontos a serem trabalhados, já que em nenhum comensal nos dias observados higienizou as mãos 
imediatamente antes do autosserviço, mesmo com a disponibilidade de um lavatório devidamente equipado na entrada do refeitório.

Almeida et al. (1995) em sua pesquisa, identificaram a presença de microorganismos patogênicos nas mãos. Dessa forma, as mãos e os utensílios manipulados pelos usuários podem transferir agentes causadores de toxinfecções aos alimentos. Greig e Lee (2009) indicam que a efetiva lavagem das mãos pode evitar a transmissão de infecções entéricas. Banczek, Vaz e Monteiro (2010) observaram que 67,7\% dos comensais de restaurantes self-service não higienizavam as mãos ou o faziam de forma inadequada, muitas vezes utilizando as próprias roupas para se secar ou entrando em contato com a superfície do lixo.

Outras fontes de patógenos para os alimentos são as gotículas de saliva emitidas ao falar, rir, tossir e espirrar. Além do couro cabeludo, roupas e o próprio corpo, possibilitando a contaminação dos alimentos (TRIGO, 1999). Sendo preocupante o excesso de conversas em cima das preparações, assim como a prática de mexer nos cabelos, coçar o couro cabeludo e outras partes do corpo. Gama, Medeiros e Chagas (2019) observaram entre comensais de dois restaurantes universitários que uma média de 27,4\% falava em cima das preparações no balcão de distribuição, sendo o segundo comportamento de risco com maior ocorrência. Ainda, 12,95\% coçavam ou tocavam parte do corpo durante o autosserviço e $7,7 \%$ mexiam no cabelo perto das preparações.

Segundo Tondo e Bartz (2011) a naso e orofaringe, ouvidos, mãos e pele são regiões do corpo onde é possível detectar a presença de Staphylococcus aureus. Esse microorganismo é um dos maiores responsáveis pelas DTAs em todo o mundo, devido à intoxicação causada por alimentos contendo suas enterotoxinas (PIGOTT, 2008).

Uma atitude frequentemente observada foi o uso do celular durante o autosserviço. Gama, Medeiros e Chagas (2019) verificaram uma ocorrência do manuseio de celular de $6,65 \%$ e de falar ao celular de $2,7 \%$. Devido a esse comportamento os micro-organismos presentes no aparelho podem ser transferidos para os alimentos. Nunes e Siliano (2016) constataram alta taxa de celulares contaminados por algum tipo de bactéria (96\%), como Staphylococcus sp., Serratia marcescens, Citrobacter freundii, Citrobacter diversus, Salmonella sp., e Escherichia coli, todas elas com potencial patogênico.

Utilizar o utensílio de uma preparação em outra para se servir, devolver alimentos do prato às cubas com a mão ou utensílio das preparações e arrumar os alimentos do prato 
com os utensílios das preparações, também foram atitudes observadas e que podem comprometer a segurança dos alimentos. Panetta et al. (2017) relatam um percentual de $33 \%$ de ocorrência da utilização do mesmo talher para se servir de diferentes preparações, e um percentual de 5,3\% de devolução de alimento do prato à travessa. Enfatiza-se que essas atitudes podem levar micro-organismos de um alimento ao outro, já que quando o utensílio é deixado dentro da preparação a parte usada para segurá-lo entra em contato com as mãos não higienizadas dos comensais, potencializando o risco de contaminação.

$\mathrm{Na}$ fase pós-intervenção, foi possível notar pequenas mudanças no comportamento dos usuários. Cerca de 10\% dos comensais passaram a lavar as mãos antes de entrarem no refeitório e as práticas de mexer nos cabelos, coçar o couro cabeludo e outras partes do corpo tornaram-se um pouco menos frequentes. Porém, não foram notadas mudanças nos hábitos de conversar sobre os alimentos e nem quanto ao uso dos celulares durante o autosserviço. Também não foram observadas modificações quanto aos atos de utilizar o utensílio de uma preparação em outra para se servir, devolver alimentos do prato às cubas com a mão ou utensílio das preparações e arrumar os alimentos do prato com os utensílios das preparações.

\section{Conclusão}

Em restaurantes self-service a contaminação dos alimentos pode ocorrer não apenas através dos manipuladores, mas também através dos consumidores, ao adotarem atitudes de risco que podem comprometer a qualidade das preparações.

Dessa forma, ressalta-se a importância da conscientização dos consumidores sobre o papel que desempenham na segurança alimentar, devendo ser uma ação contínua, contribuindo para evitar contaminações e DTAs.

\section{Referências}

AKUTSU, R. C. et al. Adequação das boas práticas de fabricação em serviços de alimentação. Rev. Nutr., v. 18, n. 3, p. 419-427, 2005.

ALMEIDA, R. C. C. et al. Avaliação e controle da qualidade microbiológica de mãos de manipuladores de alimentos. Rev. Saúde Públ., v. 29, n. 4, p. 290-294, 1995.

BANCZEK, H. F. L.; VAZ, C. R.; MONTEIRO, S. A. Comportamento dos consumidores em self-service no município de Curitiba. Rev. Bras. Tecnol. Agroindustrial, v. 4, n. 1, p. 29-41, 2010. 
CONSELHO FEDERAL DE NUTRICIONISTAS. Resolução - CFN n⿳⺈ 600, de 25 de fevereiro de 2018. Dispõe sobre a definição das áreas de atuação do nutricionista e suas atribuições, indica parâmetros numéricos mínimos de referência, por área de atuação, para a efetividade dos serviços prestados à sociedade e dá outras providências. Brasília, 2018. Disponível em: <http://www.cfn.org.br/wpcontent/uploads/resolucoes/Res_600_2018.htm>. Acesso em: 22 abr. 2019.

EVANGELISTA, J. Tecnologia de alimentos. 2 ed. São Paulo: Atheneu, 2002.

GAMA, J. L.; MEDEIROS, M. G. G. A.; CHAGAS, R. S. O. Comportamento de risco sanitário de usuários de um restaurante universitário na cidade de Niterói, RJ, Brasil. Demetra, v. 14: e38278, p. 1-16, 2019.

GREIG, J.; LEE, M. Enteric outbreaks in long-term care facilities and recommendations for prevention: a review. Epidemiol. Infect., v. 137, n. 2, p. 145-155, 2009.

HOBBS, B. C.; ROBERTS, D. Toxinfecções e controle higiênico-sanitário de alimentos. Tradução de Silvia Panetta Nascimento, Marcelo Arruda Nascimento. 1 ed. São Paulo: Varela, 1998.

LEAL, D. Crescimento da alimentação fora do domicílio. Rev. Seg. Alim. e Nutr., v. 17, n. 1, p. 123-132, 2010.

NUNES, K. O., SILIANO, P. R. Identificação de bactérias presentes em aparelhos celulares. Rev. Science in Health, v. 7, n. 1, p. 22-25, 2016.

PANETTA, M. H. et al. Restaurante com autosserviço: comportamento do consumidor $\mathrm{x}$ risco de contaminação dos alimentos. Rev. Hig. Alim., v. 31, n. 266/267, p. 37-42, 2017.

PIGOTT, D. C. Foodborn illness. Emergency Medicine Clinics of North America, v. 26, n. 2, p. 475-497, 2008.

SÁVIO, K. E. O. et al. Avaliação do almoço servido a participantes do programa de alimentação do trabalhador. Rev. Saúde Pública, v. 39, n. 2, p. 148-155, 2005.

SILVA JUNIOR, E. A. Manual de controle higiênico-sanitário em serviços de alimentação. 6 ed. São Paulo: Varela, 1995.

SMITH, J. L.; FRATAMICO, P. M. Factors involved in the emergence and persistence of food-born diseases. J. of Food Protection, v. 58, n. 6, p. 696-708, 1995.

TONDO, E. C.; BARTZ, S. Microbiologia e sistemas de gestão da segurança de alimentos. 1 ed. Porto Alegre: Sulina, 2011.

TRIGO, V. C. Manual prático de higiene e sanidade das unidades de alimentação e nutrição. São Paulo: Varela, 1999.

VEIROS, M. B.; SMITH, L. K.; PROENÇA, R. P. C. Legislação portuguesa e brasileira de segurança e higiene dos alimentos: panorama atual. Rev. Hig. Alim., v. 20, n. 115, p. 117 $128,2006$. 


\title{
IDENTIFICATION AND INTERVENTION IN RISK ATTITUDES OF USERS OF A FOOD AND NUTRITION UNIT.
}

\begin{abstract}
The study aimed to identify risk attitudes of users of the Food and Nutrition Unit (UAN) located in Botucatu, SP; correlate them to food safety and to observe if there were behavioral changes after indirect educational intervention. This is an exploratory qualitative analysis study, using a non-participant observation technique. Initially, we sought to identify the most common risk attitudes among users, to develop educational materials relating the conduct during self-service to the possible risks of contamination, and thus to verify if there were behavioral changes. Poor hand hygiene was seen as one of the most important points to work on, as none of the diner participants performed such an attitude. It was possible to observe small changes in the behavior of some users, showing that educational measures should be applied continuously for better awareness and greater effects.
\end{abstract}

Keywords: Food contamination, Consumer, Risky attitudes, Food services. 